The pattern over the past year or so certainly suggests that we will see more and more of these new approaches to synthetic transformations that have been traditionally catalysed by one or more transition-metal complexes, and that we may well continue to move from 'organometallic to orgaNOmetallic' (a cute play on words that arose during a discussion of our Suzuki chemistry with Klaus Müller from Hoffmann LaRoche). When critically assessing reports such as the recent Nature Chemistry article, one has to take into account all of the tests the authors perform to prove their case. We also need to realize that, even when performing a barrage of tests before publishing any metal-catalysed (or metal free) transformation and taking a gut-check when assessing the viability of the chemistry based on the basic tenets of science, it is still going to be difficult in some of these special cases to prove definitively what is going on.

Nicholas E. Leadbeater is in the Department of Chemistry at the University of Connecticut, 55 North Eagleville Road, Unit 3060 Storrs, Connecticut 06269 USA.

e-mail:nicholas.leadbeater@uconn.edu

\section{References}

1. Leadbeater, N. E. \& Marco, M. Angew. Chem. Int. Ed. 42, 1407-1409 (2003)
2. Leadbeater, N. E. \& Marco, M. J. Org. Chem. 68, 5660-5667 (2003).

3. Leadbeater, N. E. \& Marco, M. J. Org. Chem. 68, 888-892 (2003).

4. Leadbeater, N. E., Marco, M. \&Tominack, B. J. Org. Lett. 5, 3919-3922 (2003)

5uchwald, S. L. \& Bolm, C. Angew. Chem. Int. Ed. 48, 5586-5587 (2009).

6. Liu, W. et al. J. Am. Chem. Soc. doi:10.1021/ja103050x (2010).

7. Sun, C.-L. et al. Nature Chem. 2, 1044-1049 (2010).

8. Yanagisawa, S., Ueda, K., Taniguchi, T. \& Itami, K. Org. Lett. 10, 4673-4676 (2008)

9. Deng, G., Ueda, K., Yanagisawa, S., Itami, K. \& Li, C.-J. Chem. Eur. J. 15, 333-337 (2009).

10. Valle, F., Mousseau, J. J. \& Charette, A. B. J. Am. Chem. Soc. 132, 1514-1516 (2010).

11. Lauterbach, T., Livendahl, M., Rosellón, A., Espinet, P. \& Echavarren, A. M. Org. Lett. 12, 3006-3009 (2010).

Published online: 7 November 2010

\title{
NOBEL PRIZE 2010
}

\section{Prestige for palladium}

The synthesis of organic molecules relies on the formation of bonds between carbon atoms. In the first half of the twentieth century the reaction of an organomagnesium (Grignard) reagent with an organohalide was one of the key ways to form carbon-carbon bonds, but the high reactivity of organomagnesium can lead to unwanted side products. A significant advance in organic synthesis came with the development of transition-metal-catalysed reactions that provide more precise methods of forming carbon-carbon single bonds.

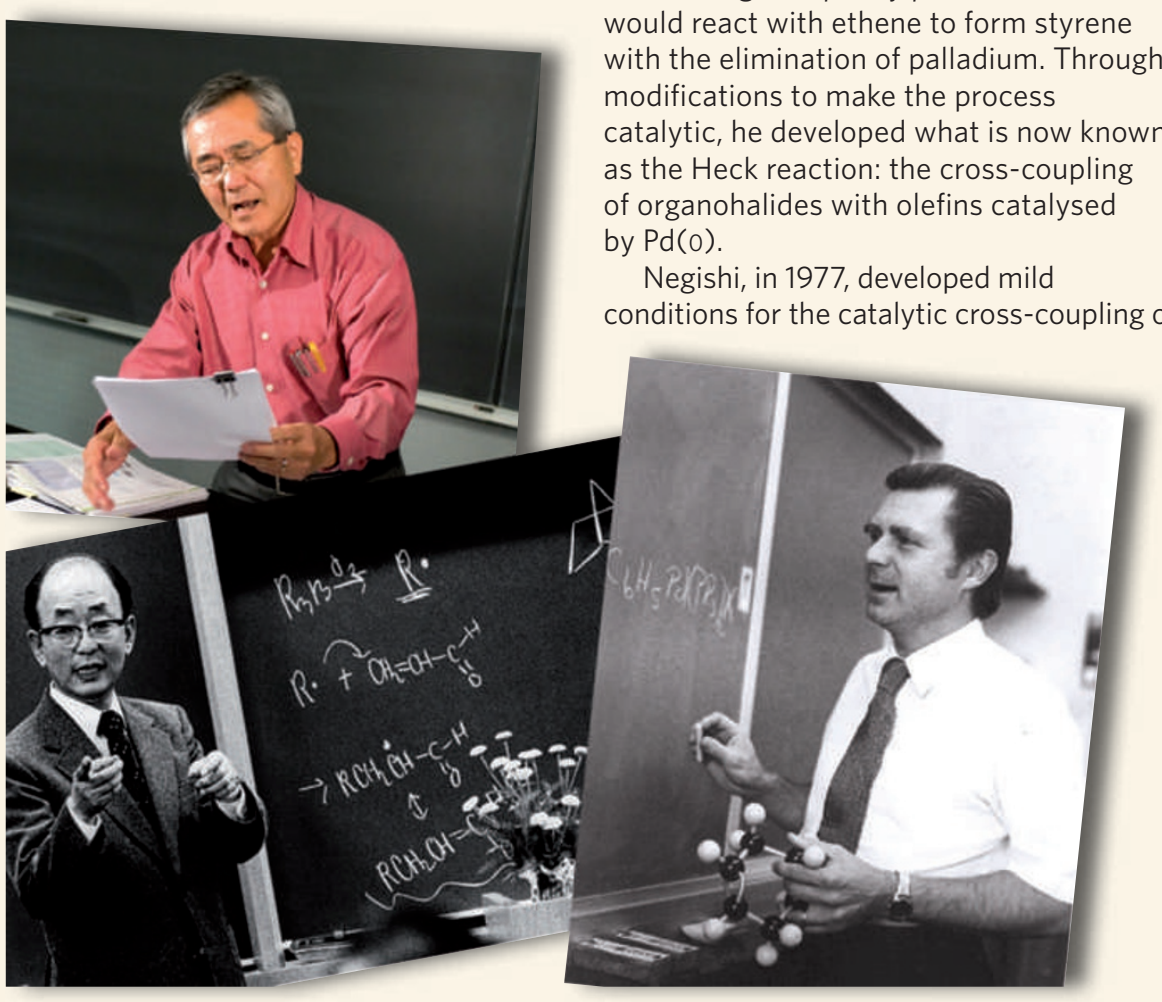

organometallics with organohalides by transmetallation with palladium. Unlike highly reactive organolithium and Grignard reagents, which are intolerant to functional groups such as those in many complex natural products, organometallics of lower reactivity - notably organozinc reagents - could be used to avoid unwanted side reactions.

In 1979, Suzuki reported the crosscoupling of organoboron reagents with aryl and vinyl halides in the presence of a palladium catalyst and a base. A significant advance in this reaction came from employing arylboronic acids and a weak base. These reactions have become a favourite of the pharmaceutical industry, thanks to the high stability and low toxicity of the reagents involved and the mild conditions required.

The reactions of Heck, Negishi and Suzuki are now ubiquitous in organic synthesis and are found in almost every undergraduate organic chemistry textbook. They offer the opportunity of planning syntheses of organic molecules using disconnections that were not previously possible. Palladium cross-couplings have become staple reactions in both academic and industrial laboratories - sparking much research in developing variations and studying their mechanisms - as well being used in the development and manufacture of many pharmaceuticals and high-tech materials.

\section{LAURA CROFT}

The original version of this story first appeared on the Research Highlights section of the Nature Chemistry website. 